\title{
LEGITIMIDADE, DEMOCRACIA E ACCOUNTABILITY NO MERCOSUL*
}

\author{
Marcelo de Almeida Medeiros
}

Neighboring states are obliged not only to treat one another according to the rules of justice and good faith, but must also, both for the sake of their own security and the common interest, create for themselves a kind of society and general republic.

François de Sallignac de la Mothe Fénelon ${ }^{1}$

\section{Introdução}

O Mercado Comum do Sul, Mercosul, completou quinze anos em março de 2006. Ele reflete, ao lado de inúmeros outros processos de organi-

* Este texto é uma versão reformulada de trabalho apresentado no XXX Encontro Anual da Anpocs, 24-28 de outubro de 2006, GT-13: "Ordem hegemônica, multilateralismo e política externa". Agradeço aos meus colegas do GT-13, assim como aos pareceristas anônimos da RBCS pelas críticas e sugestões. Elas, de fato, tornaram as idéias deste texto mais consistentes e rigorosas.

Artigo recebido em fevereiro/ 2007

Aprovado em abril/2008 zação regional internacional (ORI), a conseqüência de um processo de mutação do Estado-nação, que parece não mais conseguir atuar como primo regulador da vida social. Como atesta Deutsch:

\footnotetext{
No mundo atual, o Estado - isto é, o típico Estado-nação soberano - é simultaneamente indispensável e inadequado. Ele é um instrumento indispensável para a realização de inúmeras tarefas, para prover serviços e para lidar com muitos problemas reais. Mas ele é inadequado no gerenciamento de um número crescente de outros problemas de vida e de morte de seus cidadãos (1981, p. 331$){ }^{2}$
}

Essa mutação, no entanto, persiste ancorada em padrões interpretativos ainda por demais tributários da lógica estato-cêntrica. Tal tem sido o caso, por exemplo, das tentativas de compreensão da evolução do sistema político da União Européia, referencial contemporâneo pioneiro em matéria de inovação integracionista (Hoffmann e Van 
der Vleuten, 2007). Ora, a cartografia institucional ${ }^{3}$ que daí deriva encerra, pois, incoerências e incompatibilidades entre, de um lado, a demanda real dos atores sociais e agentes econômicos, de outro, as instituições políticas de fato concebidas e implementadas. O esforço teleológico empreendido por ambos os lados busca, contudo, um modo de governança capaz de conciliar eficiência e controle legítimo do poder.

Nesse contexto, o presente artigo propõe-se a investigar como o fenômeno da governança tem se transformado no âmbito do Mercosul. Enfocamse as complexas e imbricadas relações entre os níveis regional, nacional e, sobretudo, subnacional, privilegiando os nexos institucionais que daí derivam. A primeira parte, mais teórica, procura situar a problemática da relação entre legitimidade, democracia e accountability no terreno da governança regional e da ação dos atores estatais subnacionais. Será privilegiado o quadro político da União Européia (UE), dado que esse processo, por ser o mais aprofundado, tem sido objeto da maioria das apreciações teóricas disponíveis na literatura especializada. Apreciações essas, no mais das vezes, seminais e incontornáveis como referenciais de comparação. ${ }^{4}$ A segunda parte concentra-se, sob essa ótica, na análise empírica da relação do tandem argentino-brasileiro e no estudo da cartografia institucional e de redes de relacionamento no âmago do Mercado Comum do Sul. Aqui, a UE emerge apenas como um yardstick, um referencial exógeno, um elemento de passagem, pelo qual se transita para efetuar um melhor processo de conhecimento endógeno do Mercosul.

\section{Legitimidade, democracia e accountability versus governança regional}

Uma das críticas que mais tem assolado as organizações regionais internacionais aponta para o chamado déficit democrático. Entretanto, não raro, elas se pautam num exercício comparativo que toma como referencial o Estado-nação clássico:

Comparações são traçadas entre a UE e uma antiga, estilo-Westminster, forma de democracia deliberativa. Se essa comparação pode ser útil para propósitos filosóficos, o uso de padrões ideais que governos modernos não comportam obscurece o contexto social da política européia contemporânea (Moravcsik, 2002, p. $605) \cdot{ }^{5}$
Ora, essa falácia comparativa também tem caracterizado a análise de outros processos de integração regional - entre eles o Mercosul. É verdade que para os processos de integração regional posteriores ao Tratado de Roma o referencial comparativo deixa de ser unicamente o Estadonação, passando a ser também o próprio sistema político da União Européia, com toda complexidade do mimetismo institucional que isso implica (Meny, 1993, pp. 7-38). Assim há que se considerar na análise dos conceitos de legitimidade, democracia e accountability, no quadro mercosulino, o referencial do Estado-nação contemporâneo, de tipo cada vez mais gerenciador (Bresser Pereira e Cunill Grau, 1999, pp. 15-50), como também aquele da UE, incontornável por sua capacidade de cooptação intelectual e empirismo - sucessos e fracassos, um verdadeiro laboratório. A questão que se coloca então é: para que haja controle legítimo do poder instituído pelas organizações regionais internacionais, é imperativa a existência de participação democrática?

\section{Aspectos conceituais}

Uma das características mais marcantes do Estado-nação contemporâneo é o fato de o Poder Legislativo ter perdido, em muito, sua capacidade de legislar. Os Poderes Executivos têm, cada vez mais, feito uso de institutos legais expeditos para balizar não somente ações historicamente situadas na esfera de sua competência, por exemplo, política comercial, monetária e fiscal, mas também para efetuar incursões em outras esferas mais tipicamente ligadas ao controle parlamentar, como as de seguridade social, emprego e educação, que afetam mais de perto o dia-a-dia do cidadão. Dois exemplos, um no Mercosul e outro na União Européia, explicitam essa tendência: Brasil e França.

No Brasil, a Constituição de 1988, em seu artigo 62, baliza o poder legislativo do Executivo por intermédio do instituto da Medida Provisória (MP) que, em princípio, apenas deve ser empregado em caso de relevância e urgência. Ora, o que se observa é que o Executivo vem fazendo uso sistemático desse instrumento, ${ }^{6}$ e isso apesar das tentativas do Legislativo em limitar os abusos -, por exemplo, a Emenda Constitucional n. 32, de 11 de Setembro de 2001, a qual busca restringir o campo de utilização das referidas medidas e associá-las ao 
processo legislativo ordinário, podendo até mesmo bloquéa-lo (Art. 62, \$ 6). ${ }^{7}$ Segundo a "justificação" da Proposta de Emenda Constitucional do Deputado Carlos Souza (PP-AM), ${ }^{8}$ que propõe que o presidente da República poderá adotar por mês até três Medidas Provisórias,

[...] após a reforma em 2001, em um período de 15 meses do segundo mandato de FHC e três anos de Lula (até dezembro de 2005), o número médio de MPs subiu de três para cinco. Por outro lado, o número médio de projetos de lei manteve-se estável. [...] Antes da refor$\mathrm{ma}$, de todas as propostas legislativas baseadas em maioria simples, $28 \%$ eram MPs. Após a reforma, essa porcentagem passa para $52 \%$. Se levarmos em conta que todas as MPs enviadas ao Congresso, $79 \%$ foram aprovadas pelo plenário, isso indica que o Executivo continua governando com base em legislação extraordinária, em total desrespeito ao Legislativo.

Quiçá, estudos estatísticos mais refinados poderiam nuançar fenômenos não devidamente percebidos pela visão do supracitado deputado. A literatura nacional deles carece. Todavia, muito dificilmente eles contrariariam a propensão geral de maior expressão legislativa do Executivo brasileiro. Como assinala Limongi, "O fato é que o presidente brasileiro é poderoso do ponto de vista legislativo não porque usurpe o poder legislativo, mas porque a Constituição de 1988 assim o estabeleceu" (2006, p. 27). ${ }^{9}$

Contudo esse não é um fenômeno singular do Brasil ou da América do Sul. A França da V República também traz, em sua Constituição (1958), instrumento legislativo, a ordonnance, que guia a ação do Executivo como produtor de lei. Trata-se do artigo 38, o qual afirma que: "O Governo pode, para a execução do seu programa, pedir ao Parlamento autorização para tomar via ordonnances, durante um período limitado, medidas que são normalmente da alçada da lei". O que acontece na prática, entretanto, é que entre 1984 e 2005, 290 ordonnances foram editadas, das quais mais de dois terços desde 2000. Em 2004, o número de ordonnances editadas chega a 52 e, em 2005, a 83, ou seja, mais de um terço do total das ordonnances editadas desde 1984. Assim, durante o ano de 2005, em torno de dois terços da legislação produzida foram estabelecidos por intermédio desse instrumento do Executivo..$^{10}$ Recentemente, políticos franceses ligados aos mais diferentes matizes ideológicos - o expremiê Dominique de Villepin, do mesmo partido do presidente Sarkozy, a socialista Ségolène Royal, derrotada por ele em maio do ano passado, o líder centrista François Bayrou e Pierre Lefranc, ex-chefe-de-gabinete do presidente De Gaulle - lançaram um manifesto de alerta contra a tendência prómonarquia no estilo e nas políticas do presidente Nicolas Sarkozy. Tal manifesto alerta para "uma forma pessoal de poder que se assemelha ao de um monarca eleito", cristalizando, pois, essa propensão histórica de hipertrofia do Executivo do regime presidencial francês da V República. ${ }^{11}$

Observa-se, assim, tanto no caso francês como no brasileiro, um pendor que é menos de tipo partidário-ideológico e mais de viés burocrático-administrativo, fundamentado, entre outros, no critério de urgência, que reafirma a hipertrofia do Executivo.

Para contrabalançar essa hipertrofia do Poder Executivo em face do Poder Legislativo, assistimos a uma ascensão e politização cada vez maior do Poder Judiciário. Como assinala Carvalho: "A expansão do poder judicial é um fenômeno que tomou conta do final do século passado. A grande maioria dos países ocidentais democráticos adotou o Tribunal Constitucional como mecanismo de controle dos demais poderes" (2004, p. 115). Todavia, por ser essencialmente uma corte política cujos membros são nomeados pelo chefe de Estado/ Governo, tem quase sempre se manifestado em consonância com sua lealdade original. Donde o questionamento se trata de um verdadeiro contrapeso ou de uma degeneração da harmonia dos três poderes.

Além das fronteiras do Estado-nação, o que se observa não é diferente. Isto é, as competências supranacionais exclusivas são raras e estão quase sempre circunscritas a domínios específicos situados historicamente em esferas de exercício do Poder Executivo. Estes são os casos da Política Comercial Comum e da Política Monetária no seio da União Européia. Em ambos, o Estado-nação encontra-se alijado de sua soberania. Berlim, Paris ou Londres não decidem individualmente nesses domínios de políticas públicas. As decisões são tomadas em nível do Conselho de Ministros da UE por meio de votações por maioria qualificada. É Bruxelas quem decide. Como assinala Françoise de la Serre em relação ao projeto de integração proposto pelo Tratado de Maastricht - que de fato fundamentou os Tratados subseqüentes de Amsterdã e Nice (ainda hoje em vigor) - "A originalidade do 
projeto [da União Européia] consiste em estabelecer a coexistência, pelo menos por um tempo, de uma integração econômica de essência federal e uma cooperação [política] de inspiração confederal" $\left(1992\right.$, p. 7). ${ }^{12}$

Isso não significa, contudo, que não haja spillover e que não haja também um controle por parte das instâncias executivas nacionais. A UE e, a fortio$r i$, as ORIs mais recentes ainda limitam, em muito, suas ações a temáticas de cunho mais econômico do que político. Elas ainda existem mais para o consumidor do que para o cidadão. Não obstante, é verdade que a contaminação de setor a setor começa paulatinamente a se concretizar e que alguns domínios ligados a temas sociais, como polícia e justiça, começam a ser tratados por políticas públicas supranacionais incipientes. Esse é o caso, por exemplo, da política de vistos da UE. O Tratado de Amsterdã (1999, p. 88), em seu artigo 62, estabelece que para os vistos com duração máxima de noventa dias deverá haver uma lista comum contendo os nomes dos países que deles necessitam e os daqueles que não para penetrar nas fronteiras da União. Na verdade, foi esse dispositivo comunitário que levou a França a abolir, na última década do século passado, o visto para brasileiros, posto que nenhum outro país da UE exigia esse procedimento. A França alinhou-se, voluntariamente, antes que se visse constrangida a fazê-lo por imposição de uma decisão por maioria qualificada no âmbito do Conselho de Ministros da União.

Em algumas organizações regionais internacionais o Poder Judiciário tem se apresentado como ator capital, mesmo quando restrito a arenas específicas. Ele tem se revelado um agente indispensável da credibilidade das instituições e das políticas públicas comunitárias. Além disso, contrariamente ao que acontece com as cortes supremas de Estados-nação como o Brasil ou os Estados-Unidos, onde a lealdade do magistrado para com o Poder Executivo é deveras manifesta, as cortes supranacionais - por exemplo, a Corte de Justiça da Comunidade Européia - parecem ser menos permeáveis a esse processo de cooptação por parte do Poder Executivo (Legal, 2001).

Aquém das fronteiras nacionais, há que se sublinhar um movimento de mobilização por parte dos entes infra-estatais. Ele surge com o fito de melhor controlar a tomada de decisão nos níveis nacional e supranacional, como também com o objetivo de defender seus interesses próprios na arena internacional. Destarte, o Comitê de Regiões é criado pelo Tratado de Maastricht. Embora tenha tão-somente uma função consultiva, ele se revela um importante locus de contestação, com potencial para subsidiar novas formas de legitimidade. Essa contestação, como será visto adiante, também se dá pelo exercício constitutivo da diplomacia nacional e/ou de uma paradiplomacy.

Do imbricamento desses três níveis de competências resulta a noção de multilevel governance como definida por Banchoff e Smith: "a UE como uma política fora do molde estatal, uma constelação de instituições enquadrada numa densa e envolvente malha de interações informais que une os atores supranacional, nacional e subnacional"' (1999, p. 12). ${ }^{13}$ Malgrado o fato de a definição estar atrelada à União Européia e às suas idiossincrasias, ela pode, tomada as devidas precauções de relatividade, ser usada para a interpretação de outras organizações regionais internacionais, a exemplo do Mercosul.

A complexidade técnica, assim como a necessidade de celeridade das decisões, parece estimular formas outras de legitimidade do que apenas aquela calcada exclusivamente no controle democrático direto (via referendum) ou semidireto (via representação). Uma dessas outras formas é o que Scharpf (2000, p. 192) chama de legitimação por inputs, isto é, que o que tem dado legitimidade, de facto, ao uso do poder não tem sido necessariamente a existência do controle democrático de jure, mas sim mecanismos múltiplos e indiretos de accountability. $\mathrm{Ou}$ o que Scharpf denomina legitimação por outputs, pois para ele em termos de autodeterminação democrática o que importa é a capacidade institucional de resolução efetiva dos problemas públicos e a presença de salvaguardas institucionais contra os abusos do poder público.

Se partirmos do princípio de que a legitimidade se ancora unicamente no binômio reconhecimento e representatividade, as organizações regionais internacionais, realmente, não podem ser apontadas como legítimas. A mais avançada delas, a União Européia, revela índices muito baixos de identificação do cidadão para com ela, cidadão este cuja lealdade manifesta se dá incontestavelmente com o Estado-nação, onde de fato há um demos historicamente construído e reconhecido. Do mesmo modo, apesar dos avanços sistemáticos do Parlamento Europeu (PE) e da criação de órgãos consultivos 
como o Comitê Econômico e Social e o Comitê de Regiões, a representação mostra-se limitada pelo papel secundário dessas instituições no processo de tomada de decisão stricto sensu e pouco legitimada pela fraca participação cidadã no processo eleitoral do PE. A situação é ainda mais complicada em ORIs menos ativas politicamente e funcionando com menos elementos representativos, como é o caso do Mercosul.

No entanto, percebemos que, embora esse padrão binominal - reconhecimento e representatividade - não seja contemplado, as ORIs delineiamse como um espaço de contestação alternativo de porte. Para os atores sociais e os agentes econômicos, quaisquer que sejam sua natureza e pertencimento, a arena supranacional desponta, progressivamente, como um lugar de manifestação e exercício de desejos ligados a temáticas por vezes marginalizadas no cenário nacional e/ou subnacional. Tais são os casos, por exemplo, das temáticas ligadas à ecologia, aos direitos humanos ou ainda ao respeito dos princípios democráticos. O acquis comunitário é, a esse respeito, ilustrativo no seio da UE, pois garante aos novos membros standards mínimos de conduta e novas possibilidades de diligenciar interesses junto aos mais diversos tipos de autoridade. Também no caso do Mercosul, o Protocolo de Ushuaia, estabelecendo que "a plena vigência das instituições democráticas é condição essencial para o desenvolvimento dos processos de integração entre os Estados Partes", ${ }^{14}$ funciona como um estai exógeno relevante para a consolidação democrática no cone Sul. Na verdade pode-se falar da adoção de regimes regionais, mais estritos do que os internacionais, mas guardando os principais parâmetros conceituais destes: "Regimes podem ser definidos como conjuntos implícitos ou explícitos de princípios, normas, regras e procedimentos de tomada de decisão em torno dos quais as expectativas dos atores convergem em uma dada área das relações internacionais" (Krasner, 1988, p. 2). ${ }^{15}$

Ou seja, o potencial de contestação corrobora o entrelaçamento dos três níveis de governance e, de certa forma, forja uma legitimidade de tipo seminal entre os canais formais e informais que os permeiam. Os múltiplos regimes regionais constroem-se em função das expectativas de atores sociais e políticos, assim como de agentes econômicos, subnacionais, nacionais e supranacionais. Como Banchoff e Smith declararam: "Estas formas flui- das mais informais de representação não coincidem com os padrões de soberania popular estabelecidos pela tradicional teoria democrática. Não obstante, elas refletem a realidade da UE como política composta de múltiplas identidades enquadradas em múltiplos níveis de governança" (1999, p. 15). ${ }^{16}$

Assim, na mesma linha de Scharpf, Grant e Keohane afirmam: "Se a governança acima do nível do Estado-nação deve ser, numa Era democrática, legitimada, mecanismos apropriados de accountability precisam ser institucionalizados. Todavia, tais mecanismos não podem simplesmente reproduzir, em larga escala, os procedimentos e as práticas típicos dos Estados democráticos" (2005, p. 29). ${ }^{17}$

Partindo do pressuposto de que há dois tipos básicos de accountability ${ }^{18}$ — delegação e representação - , cada qual concebido dentro de parâmetro diferente de legitimidade, ${ }^{19}$ esses autores identificam sete mecanismos de accountability que podem ser observados nas ORIs e que, de fato, correspondem, grosso modo, aos regimes regionais acima evocados. ${ }^{20} \mathrm{~A}$ idéia é que esses mecanismos geram uma malha de proteção aos abusos de poder num sistema regional marcado por uma intensa variedade de power-wielders e por uma ausência de poder centralizado. Todavia, como sugere Majone (1996), em ORIs a accountability tem sido cada vez mais praticada não em sua forma de participação direta em processos de tomada de decisão fundados em maioria, mas via complexos sistemas de representação, seleção de delegados, socialização profissional, ex post review e equilíbrios entre setores governamentais. Isso porque se constata a necessidade progressiva de maior atenção, eficiência e expertise em áreas onde a maioria dos cidadãos permanecem racionalmente ignorantes ou pouco participantes (Moravcsik, 2002, p. 614). Ou ainda como afirma Nicolaidis e Howse: "Certamente, as fontes de legitimidade são diversas: algumas são tecnocráticas e presumem uma expertise para gerenciar as complexidades das políticas" (2001, p. 4). ${ }^{21}$

Enfim, se for possível em princípio libertarse das amarras analíticas inspiradas no Estado-nação e caso se conceba as organizações regionais internacionais como possíveis unidades de sobrevivência genuínas (Elias, 1987), pode-se considerar a probabilidade real de existir um controle legítimo do poder irradiado pelas ORIs sem que haja necessariamente participação democrática. Neste contexto de busca por legitimidade, um dos atores políticos que 
mais tem demonstrado interesse de participação são os entes subnacionais.

\section{Atores estatais subnacionais}

$\mathrm{Na}$ procura por legitimidade, um dos princípios basilares que mais tem pautado a ação da União Européia é o de subsidiaridade. ${ }^{22}$ Ele preconiza, lato sensu, que as decisões devem ser tomadas o mais próximo possível dos cidadãos. Ora, nesse sentido, e considerando os níveis subnacional, nacional e supranacional de governança envolvidos, pode-se inferir que os entes infra-estatais assumem papel de destaque. A criação do Comitê de Regiões pelo Tratado de Maastricht ilustra a galvanização institucional desse esforço legitimista (Medeiros, p. 2004). Mas ele é apenas a ponta de um iceberg. $\mathrm{Na}$ verdade, os atores estatais subnacionais vêm se mobilizando em outras frentes, talvez menos formais, no seio do Estado-nacional, como também diretamente na esfera supranacional, ${ }^{23} \mathrm{O}$ que é função das características intrínsecas de cada ator, a saber: PIB, população e território. Essa démarche gera novos modos de controle e, conseqüentemente, eleva o nível de accountability do sistema como um todo. É nessa conjunção que emergem as noções de paradiplomacy e constituent diplomacy.

Como sublinha Keating: "A globalização e o surgimento de regimes transnacionais, especialmente áreas de comércio regional, têm erodido a distinção entre negócios domésticos e estrangeiros e, ao mesmo tempo, modificado a divisão de competências entre Estado e governos subnacionais" (1999, p. 1). ${ }^{24} \mathrm{O}$ aumento da permeabilidade fronteiriça nacional expõe mais fortemente os entes subnacionais à realidade externa. E mesmo que não se possa vislumbrar (ainda) o "fim do território" (Badie, 1995), não se pode negar que sua concepção se metamorfoseia. Ele não aparece mais, como outrora, necessariamente associado ao Estado-nação e à idéia de uma soberania hermética e unívoca. $\mathrm{O}$ território hoje assume o papel de catalisador entre a sociedade e o mercado global, ao mesmo tempo em que se presta como locus para o debate político e para ações coletivas. Sua vinculação com o poder se processa de forma múltipla e, essencialmente, de acordo com uma lógica funcional. Os atores estatais subnacionais projetam-se, pois, como alternativas territoriais nessa lógica funcional. Eles atuam como um terceiro nível de poder e, dada a diminuição da capacidade de mediação do Estado-nação, com ele disputam as prerrogativas de caráter público, tanto na vertente endógena como na exógena. A ação dos atores estatais subnacionais nessa última vertente é denominada paradiplomacy.

Para Keating,

A paradiplomacia não é a mesma coisa que diplomacia, que persegue um interesse estatal bem definido na arena internacional. Ela é funcionalmente mais específica e direcionada, quase sempre oportunista e experimental. A paradiplomacia é também caracterizada por um alto envolvimento da sociedade civil e do setor privado (Idem, p. 11). ${ }^{25}$

Portanto, trata-se de um conceito que encerra, paripassu, aspirações teleológicas distintas no que concerne à ação externa e à capacidade de associação de atores locais. Capacidade que promove um aumento de accountability e, conseqüentemente, de legitimidade. A paradiplomacy não é incompatível com a diplomacia. $\mathrm{Na}$ verdade, ela atua também internamente tentando moldá-la segundo os interesses específicos de cada ator estatal subnacional.

Nesse sentido, o conflito das papeleras entre Argentina e Uruguai é ilustrativo. Como assinalam Saraiva e Medeiros:

\footnotetext{
$\mathrm{Na}$ disputa das papeleras a contenda estabelece-se entre, de um lado, o Estado uruguaio, que concentra um maior poder de decisão no caso e, de outro, um amálgama formado pelo governo nacional argentino, o governo de Entre Rios e setores da sociedade civil. Considerando a paradiplomacia como um epifenômeno no quadro uruguaio e detendo-se na problemática da questão subnacional na Argentina, a rationale desse amálgama parece repousar sobre três fatores basilares: 1) a utilização coerente do regime internacional que rege as questões ecológicas; 2) a capacidade de Entre Rios de mover uma ação coletiva paroquial conjugando interesses governamentais e não-governamentais; 3) a habilidade do governo federal de se apropriar da bandeira do movimento infra-estatal, subscrevendo-o internacionalmente (2007, p. 177). ${ }^{26}$
}

Isso reflete uma relação complexa entre poder central e subnacional, alertando, ao mesmo tempo, para o fato de que o Estado-nação ainda mantém influência determinante no gerenciamento dos negócios estrangeiros (entendidos aqui como uma imbricação entre diplomacia e paradiplomacia).

Considerando esse último aspecto como essencial e lembrando que o sufixo para remete à idéia 
de hierarquia, Kincaid sugere o uso da terminologia constituent diplomacy:

O termo constituent diplomacy procura ser um descritor neutro, evitando a idéia de que as atividades dos governos constituintes são necessariamente inferiores, subordinadas ou suplementares à high politics da diplomacia do Estado-nação. O que é high ou low politics depende da perspectiva do observador (2001, p. 74). ${ }^{27}$

Essa eqüidade original funda-se, não raro, no próprio pacto federativo. ${ }^{28}$ Inovador é o fato de que, se no passado esse pacto estabelecia uma reserva de atuação no cenário externo para as autoridades centrais, hoje se discute a pertinência da extensão dessa atuação para os atores estatais subnacionais. Conflito e competição são características intrínsecas da política interna. Então por que não podem estar presentes na política externa? Por que suprimi-los? O que parece remanescer é o mito da já referida soberania hermética e unívoca usada pelos governos nacionais para dar legitimidade a tal supressão. Como lembra Kincaid: "mesmo que a competição exista, e exista legitimamente em outros campos da política, nos negócios estrangeiros a reação instintiva das elites nacionais é tentar suprimir a competição e proteger a concepção da política externa detrás do véu do segredo de Estado" (Idem, p. 61). ${ }^{29}$ Argumenta-se que os atores estatais subnacionais não agiriam, necessariamente, sob o veil of ignorance, ${ }^{30}$ o que provocaria a defesa de interesses individuais e não do interesse geral, reduzindo, assim, o grau de legitimidade da ação. Contudo, o temps mondial da democracia de mercado (Laïdi, 1993), estabelecido no final do século XX, mostrase distinto daquele que pautou o design vestifaliano do cenário internacional. Nele os dispositivos de controle de poder procuram se coadunar com a interdependência complexa (Keohane e Nye, 1987) fornecendo novos mecanismos de accountability externa por meio da constituent diplomacy.

Todavia não se pode esquecer de assinalar que, em artigo seminal publicado na International Organization em 1988, Putnam já sinalizava para essa vertente interna da constituent diplomacy, imaginando a relação entre diplomacia e política doméstica segundo uma lógica de jogo em dois níveis:

A política de várias negociações pode ser utilmente concebida como um jogo de dois níveis. No nível nacional, grupos domésticos perseguem seus interesses pres- sionando o governo para adotar políticas favoráveis, enquanto os políticos buscam o poder costurando coalizões no interior destes grupos. No nível internacional, governos nacionais tentam maximizar suas próprias habilidades a fim de satisfazer as pressões domésticas, enquanto os políticos procuram minimizar as conseqüências adversas deste nível de negociação. Nenhum desses dois jogos pode ser ignorado pelos tomadores centrais de decisão, na medida em que seus países se mostram interdependentes, ainda que soberanos (1988, p. 434$){ }^{31}$

Essa lógica, contudo, não focava, stricto sensu, a ação dos atores estatais subnacionais, como o fez em seguida o conceito de constituent diplomacy.

Em resumo, constata-se que: (1) algumas organizações regionais internacionais estão dotadas de instrumentos de controle de poder que garantem uma legitimidade que repousa essencialmente sobre uma malha de accountability das políticas públicas supranacionais. Standards, sanções e informações constituem o tripé que assegura a legitimidade destas políticas públicas; (2) as ORIs estão funcionando como um espaço alternativo de contestação e, assim, podem ser consideradas, de certa maneira, um vetor propulsor de legitimidade; e (3) dentro do espírito de subsidiaridade revisitado pela União Européia, ${ }^{32}$ os atores estatais subnacionais revelamse um elo importante entre o cidadão e os poderes nacional e supranacional. Eles atuam, no que tange a seus interesses exógenos, por meio da constituent diplomacy que, apesar de incipiente, reforça os parâmetros de legitimidade do sistema.

\section{A experiência do Mercosul}

O Mercado Comum do Sul surge num momento de redemocratização da América Latina (Camargo, 2006). Ele não poderia, pois, deixar de refletir no seu âmago um interesse precípuo pela vigência de princípios democráticos. Em face da malograda experiência do Pacto Andino, cujas instituições se anteciparam à capacidade de subordinação de facto dos Estados-nação, o Mercosul hesita em se lançar em projetos institucionais que não correspondam à real capacidade de comprometimento de seus Estados-membros. Apesar disso, o Mercado Comum do Sul abriga uma dinâmica política autêntica que mescla, formal e informalmente, uma multitude de redes e atores. Entre eles, os atores estatais subnacionais começam, paulatinamente, a 
ocupar mais espaço e a tecer suas próprias redes através de uma constituent diplomacy favorecida por reformas constitucionais ocorridas na Argentina e no Brasil (Vigevani et al., 2004). Todavia, como alhures, a relação destes atores com o poder central no seio do Mercosul não é simples. Segundo Kulgemas e Branco:

Duas forças convivem e se tensionam na relação entre
o governo central e as províncias: uma tendência centrí-
peta, que procura reter o poder para o governo central,
não impedindo ações autônomas das unidades subna-
cionais, mas regulando e controlando; e a tendência
centrífuga, que mostra a ação das unidades subnacio-
nais em buscar maior autonomia política e econômica
para seus interesses próprios, facilitadas pelas crescen-
tes assimetrias na distribuição dos recursos internos e
pelas oportunidades de negócios abertas com os efeitos
decorrentes da globalização $(2005$, p. 169$)$.

Essa relação de forças e seus pressupostos de legitimidade ancoram-se essencialmente na relação do tandem argentino-brasileiro, sendo também função da cartografia institucional e das redes de relacionamento.

\section{$O$ tandem argentino-brasileiro}

Antes de tudo, é preciso ressaltar que Argentina e Brasil representam, grosso modo, 95\% do PIB do território e da população do Mercado Comum do Sul. ${ }^{33}$ E que o Brasil, sozinho, representa, grosso modo, 2/3 dessas mesmas variáveis. Além dessa heterogeneidade abissal de natureza exógena, pode-se igualmente identificar uma heterogeneidade endógena não menos considerável. A Patagônia argentina, o Nordeste brasileiro ou o Chaco paraguaio, contrastando com regiões bem mais desenvolvidas desses mesmos países como, respectivamente, Buenos Aires, São Paulo ou ainda Assunção. Assim, identifica-se no Mercosul uma lógica de centroperiferia em níveis múltiplos (Medeiros, 2003, p. 155) que gera intensas dificuldades para o funcionamento das instituições mercosulinas, até o momento caracterizadas por mecanismos intergovernamentais de tomada de decisão consensual. Além disso, contrariamente à União Européia, o Mercado Comum do Sul não possui orçamento próprio, o que o impede, em parte, promover uma integração positiva (Scharpf, 1996, p. 15) e de atuar como vetor redistributivo, o que erode, obviamente, os fundamentos de sua legitimidade.
Daí deriva que as transformações institucionais mercosulinas tem sido tributárias da convergência existente no âmbito do tandem Brasil-Argentina. Quando ela se verifica, nota-se um efeito de atração que se processa em relação aos demais parceiros que reconhecem um custo por demais elevado em adotar uma postura opting out of. Eles são quase que comercialmente aspirados. Esse é o caso especialmente do Paraguai e do Uruguai, ambos economicamente assaz dependentes das decisões de Brasília e Buenos Aires. Como indicam Cervo e Bueno: "Desde o início da década de 1990, o Brasil traçou uma estratégia regional que permaneceria invariável: o reforço do Mercosul com convergência política entre Brasil e Argentina e organização do espaço sul-americano com autonomia perante os Estados Unidos" (2002, p. 486). Claro que nem sempre essa estratégia é compartilhada pela política externa portenha, o que tem, evidentemente, incidido na evolução do Mercado Comum do Sul. Como aponta Paulo Nogueira Batista Jr.:

Nos tempos de Carlos Menem e Domingo Cavallo, na
década de 1990, a minha preocupação central era que
os argentinos pudessem ser arrastados para a dolariza-
ção total e a subordinação completa aos Estados Uni-
dos, contaminando em alguma medida a posição brasi-
leira e solapando de vez a integração sul-americana.
Depois, sobreveio a crise terrível de 1999-2002, uma
das piores de que se tem notícia (2007, s/p).

Essa última, não se pode olvidar, causada, entre outras coisas, pela desvalorização do Real realizada unilateralmente pelas autoridades monetárias brasileiras. Por outro lado, a dinâmica do tandem Brasil-Argentina mostra-se muito expressiva nas negociações da Área de Livre Comércio das Américas - Alca ante os Estados Unidos. Como nota Tulchin: "Mais significativo no longo prazo foi a sofrida e lenta negociação para incluir a Argentina e o restante do Mercosul na área de livre-comércio formada pelos Estados Unidos, México e Canadá” (1998, p. 187). ${ }^{34}$

Sob uma ótica neo-institucionalista, o Mercosul parece poder ser compreendido dentro de uma visão dita de second movement, ${ }^{35}$ ou seja, como um fenômeno simultaneamente tributário de um path dependence, de uma escolha racional e de elementos cognitivos que permeiam o entendimento da sociedade civil. O intergovernamentalismo exacerbado deve-se a um apego histórico, mas recen- 
te, ao exercício da soberania conquistada após os processos de descolonização no primeiro quartel do século XIX, e a uma quase ausência de conflitos bélicos de porte que pudessem ter estimulado os Estados-nação do cone Sul, como foi o caso na Europa, a admitir com menos reticência limitações de soberania. ${ }^{36}$ O Estado-nação sul-americano é, ainda hoje, deveras enraizado em sua fórmula fundadora de centralidade, ${ }^{37}$ em que os atores estatais subnacionais têm reduzida margem de manobra. Por outro lado, não se pode negar que esse poder centralizado tem agido segundo uma análise fina da relação custo/benefício. Apesar da integração mercosulina ser assimétrica e, a curto prazo, concentrar os ganhos e socializar os prejuízos, ela é levada a cabo por ser considerada pelos seus componentes, a longo prazo, um projeto recompensador do ponto de vista político e/ou econômico. Ainda, apesar dos percalços de legitimidade que a centralidade possa engendrar, as sociedades civis dos Estados-partes não percebem o Mercosul de forma negativa, contrariamente ao que acontece, por exemplo, com a visão da Área de Livre Comércio das Américas - Alca. É como se a fase pragmática da integração sul-americana (Barbosa, 1996, p. 135), iniciada em meados dos anos de 1980, contivesse ainda um ranço romântico no imaginário dos povos e tomadores de decisão - o sonho bolivariano ainda remanescente. ${ }^{37}$ Esse reconhecimento difuso no imaginário do povo sul-americano funciona como um substrato potencial para o desenvolvimento legítimo da construção integracionista.

A volta dos regimes democráticos ao cone Sul e as reformas constitucionais argentina e brasileira são fatores determinantes para a alteração das configurações de governança. Internamente, o regime autoritário esgotara sua capacidade de legitimação via incremento econômico; na verdade uma pseudo-legitimação por outputs, visto que a presença de salvaguardas institucionais contra os abusos do poder público inexistiam. Externamente, imunes ao hermetismo intrínseco que marca os caudilhismos, Argentina e Brasil se aproximam, inaugurando pragmaticamente uma parceria inédita (Almeida, 1998). O objetivo é pensar uma re-fundação do Estado-nação sobre bases democráticas e em função da nova realidade competitiva internacional (Vaz, 1999). O Mercado Comum do Sul surge, então, na qualidade de condições intermediárias de contorno, um catalisador pedagógico e con- tributivo para um novo arranjo institucional (Medeiros, 2000).

A Constituição brasileira de 1988 apresentase como descentralizadora. Uma tendência natural após duas décadas de centralismo, em que as unidades da federação, assim como as municipalidades, pouco tinham como margem de manobra. Em seu art. 18 estabelece: "A organização políticoadministrativa da República Federativa do Brasil compreende a União, os Estados, o Distrito Federal e os Municípios, todos autônomos, nos termos desta Constituição". Como assinala Frazão: "A Constituição de 1988 estende até certo ponto a competência legislativa dos estados. Ela também beneficia as autoridades municipais desta extensão" (1994, p. 318). ${ }^{39}$ Destarte, os atores estatais subnacionais brasileiros adquirem a possibilidade de maior atuação política nacional e, ao menos em princípio, na internacional, na medida em que também a Constituição de 1988 atesta, em seu art. 4: "A República Federativa do Brasil buscará a integração econômica, política, social e cultural dos povos da América Latina, visando à formação de uma comunidade latino-americana de nações". Os elementos para a prática de uma constituent diplomacy são assim lançados e, de fato, em 1997, Fernando Henrique Cardoso cria a Assessoria de Relações Federativas - ARF no gabinete do Ministro das Relações Exteriores para estimular a aproximação com estados e municípios via escritórios regionais. ${ }^{40} \mathrm{No}$ Governo Lula, a ARF transmuta-se em Assessoria Especial de Assuntos Federativos e Parlamentares - AFEPA e cria-se uma Subchefia de Assuntos Federativos com o objetivo de coordenar as ações do Executivo com as dos estados e municípios. Esses últimos, então, assumem um papel pró-ativo nas relações exteriores dentro das suas respectivas competências constitucionais, podendo, de tal sorte, englobar políticas públicas no setor de saúde, educação, cultura, meio-ambiente, transportes, entre outros. É exatamente essa Subchefia, vinculada à Secretaria de Relações Institucionais, que co-organiza com o seu homólogo argentino, em maio de 2007, o Seminário de Tucumán, reunindo os governadores do Nordeste brasileiro e do Noroeste argentino para discutir parcerias nas mais diversas áreas. ${ }^{41}$

A República Argentina, genuinamente um Estado-nação federal, ${ }^{42}$ efetua, em 1994, uma reforma constitucional que irá tanto interna como 
externamente ter repercussões relevantes. $\mathrm{O}$ art. 24 da nova carta permite a aprovação de tratados de integração "que deleguem competências e jurisdição a organizações supra-estatais em condicões de reciprocidade e igualdade, e que respeitem a ordem democrática e os direitos humanos. As normas daí derivadas têm hierarquia superior às leis". ${ }^{43}$ Essa inovação deixa clara a possibilidade de predominância do direito comunitário sobre o nacional dentro de uma visão clássica vislumbrada pela teoria monista (Kelsen, 1992, p. 352). Por outro lado, o art. 124 estabelece que as províncias poderão "celebrar convênios internacionais desde que não sejam incompatíveis com a política exterior da Nação e não afetem as faculdades delegadas ao governo federal ou o crédito público da Nação; com conhecimento do Congresso Nacional". ${ }^{44} \mathrm{O}$ que, como no caso brasileiro, confere uma margem de atuação dos atores estatais subnacionais argentinos bem mais conseqüente do que no passado.

De tal modo, as visões argentina e brasileira associam democracia e descentralização, ao mesmo tempo em que as articulam à idéia de eficiência. O gerenciamento não tem sido simples. O forte clientelismo ainda presente nas esferas locais e o despreparo das suas burocracias têm dificultado sobremaneira os mecanismos de governança. Em nível interno, alguns dispositivos de accountability tiveram que ser criados para estancar apropriações privadas de bens públicos e atos de corrupção, como por exemplo a Lei de Responsabilidade Fiscal no Brasil. ${ }^{45}$ A dilatação da capacidade participativa dos atores estatais subnacionais passaria assim a contribuir para a legitimidade do processo político nacional de forma restrita se, somente se, associada a mecanismos rigorosos de controle. A legitimidade estaria, pois, forjada por uma accountability miscigenada, combinando, pari passu, participação e delegação. A dinâmica mercosulina oferece um canal alternativo para a movimentação dos atores estatais subnacionais e funciona como um suporte complementar à accountability nacional.

\section{Cartografia institucional e redes de relacionamento}

O Mercosul, desde seus primórdios, tem estimulado a discussão sobre a refundação dos pactos federativos de Argentina e Brasil, permitindo que o diálogo entre seus atores estatais subnacionais se intensifique. Essa intensificação vem se dan- do mediante duas formas principais: a primeira constitui-se numa tentativa de maior participação nas instituições formais do Mercosul; a segunda por meio da articulação de redes. É dessa forma que os atores estatais subnacionais atuam na governança do Mercado Comum do Sul.

Trata-se de uma via de mão dupla retroalimentada, como ilustra o diagrama da página seguinte: Democracia e livre-mercado nos Estadosnação (inputinterno) promovendo descentralização com accountability internamente (output interno) e integração regional externamente (output externo); essa integração regional, por sua vez, contribuindo: (i) para a consolidação da descentralização como locus para a ação das unidades subnacionais [input $(\mathrm{A}+\mathrm{P} 1+\ldots+\mathrm{Pn})+(\mathrm{B}+\mathrm{P} 1+\ldots+\mathrm{Pn})]$; $\mathrm{e}$ (ii) para o aumento da accountability do multilevel governance do sistema como um todo. Esse todo está inserido dentro dos regimes internacionais (representado, no diagrama, pelo fundo branco circunscrito pelo enquadramento retangular). A constituent diplomacy encontra-se representada nas expressões input $(\mathrm{A}+\mathrm{P} 1+\ldots+\mathrm{Pn})$ e $(\mathrm{B}+\mathrm{P} 1+\ldots+\mathrm{Pn})$, ou seja, a ação sobre o Mercosul de uma política externa argentina e/ou brasileira composta pelas componentes federal e subnacional. A paradiplomacy, por sua vez, mostra-se mais vinculada aos relacionamentos entre os Atores Estatais Subnacionais - AES (estados e municípios brasileiros e províncias e municípios argentinos) representados no diagrama pelas redes, a saber: AES1, AES2, AESn.

Dentro das instituições formais do Mercosul, apenas em 2004 os atores estatais subnacionais obtêm, de jure, prerrogativa de participação, quando, em Belo Horizonte, o Conselho Mercado Comum (CMC) decide: "Criar o Fórum Consultivo de Municípios, Estados Federados, Províncias e Departamentos do Mercosul, com a finalidade de estimular o diálogo e a cooperação entre as autoridades de nível municipal, estadual, provincial e departamental dos Estados Partes do Mercosul". ${ }^{46}$ Esse fórum ${ }^{47}$ sucede, na verdade, a Reunião Especializada de Municípios e Intendências (REMI) criada em 2000 por resolução do Grupo Mercado Comum (GMC). ${ }^{48}$ Ele, porém, é mais abrangente, englobando não apenas os municípios e intendências, mas também províncias, estados federados e departamentos, geralmente níveis de poder mais desenvolvidos dentro de um sistema federal. Também não é anódino o fato de a REMI ter sido 


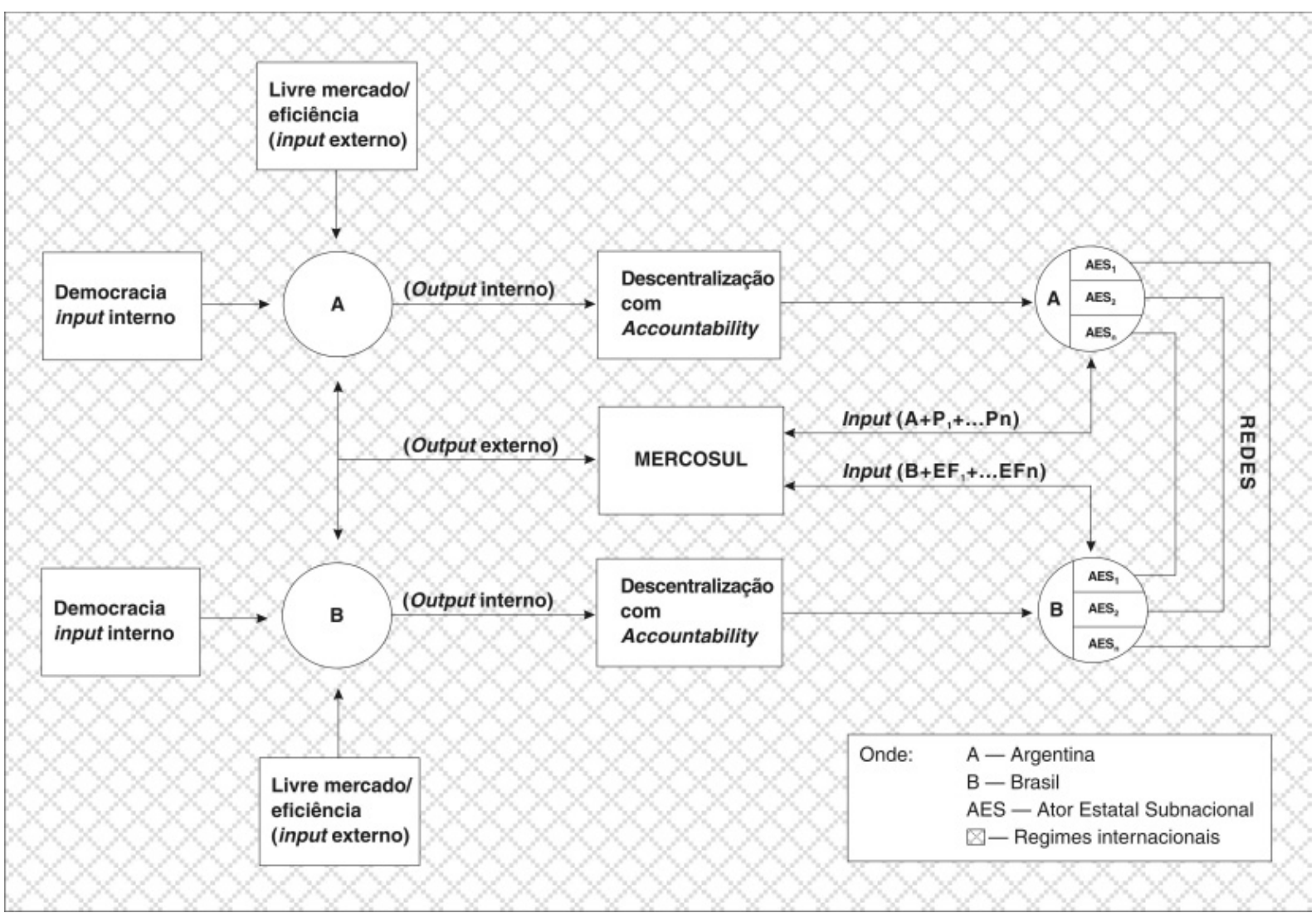

Diagrama elaborado pelo autor (EF - Estado Federado e/ou Município brasileiro e P - Província e/ou Município argentino).

criada por uma resolução do GMC, e do fórum ter sido instituído por uma decisão do CMC. O teor político da decisão é muito mais forte do que o da resolução, posto que expressa a vontade direta dos chefes de Estado. Ainda, pode-se assinalar que o fórum tem status de instituição plena do Mercosul e, portanto, mais perene, enquanto a REMI, apenas de reunião, com vocação mais efêmera. Dados os problemas de heterogeneidade enfrentados pela unicidade do Comitê de Regiões na UE, o FUES é formado por um comitê de municípios e um comitê dos estados federados, províncias e departamentos. Com o que se espera uma maior fluidez no diálogo e nas manifestações de interesses. O fórum pode propor ao GMC medidas destinadas à coordenação de políticas para promover o bem-estar e melhorar a qualidade de vida dos cidadãos.

Entretanto, essa participação mais direta dos atores estatais subnacionais no quadro institucional mercosulino foi precedida de atividades de relacionamento no seio de duas redes: Crecenea/Codesul e Mercocidades. A rede composta pela Comissão Regional de Comércio Exterior do Nordeste Argentino (Crecenea) e pelo Conselho de Desenvolvimento e Integração Sul (Codesul) reúne em cimeira duas vezes por ano, desde junho de 1995, os governadores das províncias do Nordeste argentino e dos estados do sul e centro-oeste brasileiros. Esta cimeira vai bem além dos desafios estritamente administrativos e constitui um ato político no qual os atores estatais subnacionais proclamam a importância de seus papéis no processo da governança regional. Eles alegam ser o elo mor na cadeia de políticas públicas e detentor, ao lado do poder central, de competências, como acima referenciado, em áreas de integração como educação, cultura, meio ambiente e transportes. Por outro lado, a rede das mercocidades foi estabelecida em novembro de 1995 por dezenove cidades do Mercosul e do Chile. 
Não muito diferente da percepção do Crecenea/ Codesul, esta rede considera que o objetivo primordial da integração reside na participação cidadã e que, conseqüentemente, as cidades devem, em matéria de sua competência, associar-se ao processo de decisão das instituições do Mercosul. Para tal, as mercocidades criaram nove comissões temáticas que procuram desenvolver projetos de cooperação que encorajem uma microlocalização das atividades industriais, mercantis e de serviços (arranjos produtivos locais, clusters etc.) no seio do Mercado Comum do Sul.

Um instrumento importante que poderá reforçar o papel dos atores estatais subnacionais é o Fondo para la Convergência Estructural del Mercosur (Focem). Criado pela Decisão CMC n. 45/ 04 , ele tem como objetivo financiar programas para promover a convergência estrutural, desenvolver a competitividade, promover a coesão social das economias menores e regiões menos desenvolvidas e apoiar o funcionamento da estrutura institucional e o fortalecimento do processo de integração. Esse fundo é constituído de aportes anuais de cem milhões de dólares por parte dos Estados-partes, a Argentina contribuindo com $27 \%$, o Brasil com $70 \%$, o Paraguai com $1 \%$ e o Uruguai com $2 \%$. Contrariamente aos fundos estruturais da UE, o Focem está sujeito à discricionariedade contributiva dos Estados-partes, o que diminui o grau de independência da estrutura supranacional. Contudo, ele sinaliza para uma possível participação efetiva dos atores estatais subnacionais no seu gerenciamento, na medida em que toca em competências constitucionalmente a eles atribuídas. Além disso, o Focem, por meio de sua ação redistributiva, poderá colaborar também para um aumento da legitimidade que cresceria tanto no que diz respeito ao seu viés participativo, como àquele relacionado com um acréscimo do nível de accountability.

\section{Considerações finais}

Observa-se, de tal modo, seja formalmente, seja através de redes, que os atores estatais subnacionais têm compartilhado da governança regional mercosulina. Eles são reconhecidos pelos próprios Estados nacionais como entes capitais para a consecução da prática democrática - pelo menos quando esta se dá aquém de suas fronteiras. Além delas, o posicionamento é bem mais mitigado e o poder central hesita em se desfazer de suas competências originais. Como escreve Keating: "oportunidades para as regiões agirem na Europa continuam limitadas, sendo ainda os estados os atores dominantes" (1999, p. 7)..$^{49}$ Inclusive o Tratado de Lisboa, atualmente em processo de ratificação pelos Estados-membros, traz consigo uma evidência de que o Estado-nação insiste em manter-se como ator de monta na arena comunitária: o "Protocolo relativo ao papel dos Parlamentos Nacionais na União Européia". Este protocolo visa a "incentivar uma maior participação dos Parlamentos nacionais nas atividades da União Européia e reforçar a sua capacidade de exprimirem as suas opiniões sobre os projetos de atos legislativos da União Européia e sobre outras questões que para eles possam revestir especial interesse". ${ }^{50}$ Dessa forma, introduz-se, nas engrenagens institucionais da União, mais um ator estatal, ao lado do já hipertrofiado poder do Conselho, reforçando-se, portanto, a lógica intergovernamental em detrimento da supranacional. Mesmo que, como alega a Comissão, isso aconteça paralelamente a um aumento de poder do Parlamento Europeu" e com o objetivo de "desenvolver a democracia e aumentar a legitimidade do funcionamento da União". ${ }^{52}$

No Mercosul a situação é ainda mais limitada. A influência dos atores estatais subnacionais se dá por uma constituent diplomacy restrita à sua ação interna junto ao Executivo federal (diplomacia federativa para o Itamaraty). Apesar disso, não se pode negar a existência de uma interconexão crescente entre os diversos níveis políticos, gerando, de fato, uma multilevel governance, em que, de uma maneira ou de outra, os atores estatais subnacionais atuam (ver Diagrama supra), mesmo que não se possa ainda falar de níveis coadjuvantes de governança. Também não se pode refutar que o Mercado Comum do Sul tem se apresentado como um espaço de contestação alternativo, constituindo-se, desse ponto de vista, como um bastião de legitimação, como demonstra a criação do Foro Consultivo de Municípios, Estados Federados, Provincias y Departamentos del Mercosur.

Salomón e Nunes estudando o caso da atuação do estado do Rio Grande do Sul e da cidade de Porto Alegre no âmbito do Mercosul e revisitando os estudos de Hocking (2004), Paquin (2004) e Rosenau (1990) concluem 
[...] que, tanto os governos regionais, como os locais, podem ser considerados atores internacionais mistos, em parte condicionados pela soberania que compartilham com outros governos no território que administram, mas também mais livres que os governos centrais no que diz respeito a suas opções de política exterior, com algumas pautas de atuação semelhantes às dos atores não estatais $(2007$, p. 139).

Essa condição faz do ator subnacional um elo relevante na cadeia das políticas públicas relacionadas com a arena regional e/ou internacional. E isso tanto no que concerne ao processo de democratização das ações, como no que diz respeito aos procedimentos de legitimação e accountability.

Sem embargo, como assinala Jenkins, "uma das questões mais duvidosas da nossa Era [é] se a globalização está drenando o sangue político do Estado-nação: sua soberania" (2003, p. 63). ${ }^{53} \mathrm{O}$ peculiar é que, tanto a tradição transnacionalista, como a realista, ambas na expectativa de responderem a essa questão, apontam e reconhecem a emergência dos atores subnacionais na arena internacional como elemento relevante para esse debate, se bem que por motivos distintos. Enquanto a primeira aponta essa emergência como uma perda de soberania do Estado-nação no que concerne aos negócios externos (Ohmae, 1995), a segunda percebe o fenômeno como uma mera reconfiguração do Estado-nacional a fim de melhor responder às novas exigências da globalização (Shipman, 2002), ou seja, como sugere Slaughter: "O Estado não está desaparecendo, ele está se desagregando por meio dos componentes que o formam" (1999, p. 178). ${ }^{54}$

Entretanto, o que se observa, em ambas as visões, é que o Estado-nação não se apresenta mais como o único depositário dos elementos reguladores da sociedade. Nesse sentido, Held anota que:

Considerando que grupos se sentem humilhados por forças globais e por regimes políticos impróprios ou sem efetividade, novas demandas por autonomia regional e local são feitas. [...] Eles vislumbram uma ordem política de associações, cidades e nações democráticas, assim como de regiões e malhas globais. Nesta ordem, o princípio da autonomia estaria ancorado em diversos loci de poder e na interseção de vários domínios espaciais (1996, p. 357)..$^{55}$

Fazendo com que esses outros níveis de governança - o supra e o subnacional - operem como loci genuínos e complementares de legitimidade e accountability.
É o que se observa na evolução do Mercosul. Ela, como um todo, demonstra uma preocupação de conciliação entre eficiência institucional e prática democrática. A fórmula parece passar por uma nanoaccountability, ou seja, uma accountability multipontual que mescle participação e delegação em medida ideal. Como afirma Félix Pena se referindo à idéia de uma nova etapa na integração mercosulina marcada pela criação do Parlasul e do Tribunal Permanente de Revisão, "se iniciou o caminho de um necessário aperfeiçoamento institucional do processo de integração" $(2005, \mathrm{~s} / \mathrm{p}) .{ }^{56}$

\section{Notas}

1 Apud Brown, Nardin e Rengger (2002, p. 301).

2 "In this present-day world, the State - and this is typically the more or less sovereign national state - is both indispensable and inadequate. It is indispensable instrument to get many things done, to provide many needed services and to deal with many real problems. But it is inadequate to cope with an increasing number of other problems of life and death for many of its inhabitants".

3 Entendemos por cartografia institucional não apenas o conjunto de instituições formais e informais, mas também os modos de relacionamento existente entre elas. Esse conjunto dinâmico é de natureza reticulada, constituindo-se em uma malha de regimes de poder.

4 Tentamos, em termos de revisão bibliográfica, privilegiar as idéias matrizes relacionadas com a problemática analisada. Constatou-se que a maior parte da literatura pertinente não é brasileira. Isso não significa que autores nacionais não foram utilizados, mas apenas que o foram quando se tratava de argumentos inovadores ou aplicados a realidade mercosulina.

5 "Comparisons are drawn between EU and an ancient, Westminster-style, or frankly utopian form of deliberative democracy. While perhaps useful for philosophical purpuses, the use of idealistic standards no modern governments can meet obscures the social context of contemporary European policy-making”.

6 A lista completa de todas as Medidas Provisórias está disponível no site http://www.planalto.gov.br/ccivil/ MPV/Quadro/_Quadro\%20Geral.htm\#posteriorec (acessado em 14/2/2008).

7 Essa emenda está disponível no site http://www. planalto.gov.br/ccivil_03/Constituicao/Emendas/ Emc/emc32.htm (acessado em 14/2/2008).

8 Disponível no site http://www.camara.gov.br/sileg/ integras/456085.pdf (acessado em 14/2/2008). 
9 Limongi ainda afirma: "Propositalmente, deixei por último a arma mais poderosa com que conta o presidente, o poder de decreto, a medida provisória, para mostrar que se trata de um entre outros tantos recursos à disposição do presidente. $\mathrm{O}$ mais poderoso sem dúvida alguma, pois altera unilateralmente o status quo" (2006, p. 27).

10 O Senado francês procedeu em 10 de fevereiro de 2006 a uma análise histórica do recurso às ordonnances durante a V República. Informação disponível no site http:/ /www.agoravox.fr/article.php3?id_article $=7600$. php3?id_article $=61$ (acessado em 14/2/2008).

11 Cf. Folha de São Paulo, "Manifesto dá a Sarkozy estilo monárquico", no site http://www1.folha.uol.com.br/ fsp/mundo/ft1802200820.htm (acessado em 18/2/ 2008).

12 'L'originalité du projet [de l'Union Européenne] consiste à faire coexister, au moins pour un temps, une intégration économique d'essence fédérale et une coopération [politique] d'inspiration confédérale".

13 " [. . . the EU as a fluid polity outside the statist mold, a constellation of institutions embedded in a dense and evolving network of informal interactions that brings together supranational, national and subnational actors".

14 Artigo $1^{\circ}$ do Protocolo de Ushuaia sobre Compromisso democrático no Mercosul, Bolívia e Chile (cf. site http://www2.mre.gov.br/dai/ushuaia.htm [acessado em 25/4/2006]).

15 "Regimes can be defined as sets of implicit or explicit principles, norms, rules and decision-making procedures around which actors' expectations converge in a given area of international relations".

16 "These more informal, fluid forms of representation do not meet the standards of popular sovereignity set by traditional democratic theory. Nonetheless, they reflect the reality of the EU as polity composed of multiple identities embedded at multiple levels of governance".

17 "If governance above the level of the nation-state is to be legitimate in a democratic era, mechanisms for appropriate accountability need to be institutionalised. Yet these mechanisms cannot simply replicate, on a larger scale, the familiar procedures and practices of democratic states".

18 Usamos a definição de Grant e Keohane para accountability: "como nós usamos, implica que alguns atores têm o direito de responsabilizar outros atores em relação a um conjunto de padrões, de julgar se eles assumiram suas responsabilidades em relação a esse conjunto de padrões, de impor sanções se eles consideram que essas responsabilidades não foram assumidas" $(2005$, p. 1). ["as we use the term, implies that some actors have the right to hold other actors to a set of standards, to judge whether they have fulfilled their responsibilities in light of these standards, and to impose sanctions if they determine that these responsibilities have not been met".]

"No modelo de participação, os que são afetados controlam os detentores de poder diretamente por meio da participação, ao passo que no modelo de delegação, os que delegam poder tornam os detentores de poder responsáveis mediante uma variedade de mecanismos de julgamento ex post') (Grant e Keohane, 2005, pp. 3233). ["In the participation model, those affected hold power-wielders accountable directly through participation, whereas in the delegation model, those delegating power hold power-wielders accountable through a variety of mechanisms for judgment after fact".]

20 São eles: Hierarchical, Supervisory, Fiscal, Legal, Market, Peer and Public reputational (Grant e Keohane, 2005, p. 36)

21 "Surely, the sources of legitimacy are diverse: some are technocratic, and relate to presume expertise to manage the complexities of policies".

22 Preâmbulo do Tratado da União Européia e artigo 5 do Tratado da Comunidade Européia consolidados em Nice em 2002. Título III, artigo I-11 do Tratado estabelecendo uma Constituição para a Europa (este Tratado não foi aprovado pelos referenda realizados na França e nos Países Baixos em 2005).

23 É considerável o número de escritórios de representação e de missões regionais em Bruxelas. Seu trabalho de divulgação e lobby tem assumido proporções relevantes. Vale também lembrar que o Tratado de Maastricht estabeleceu não só a possibilidade, em circunstâncias específicas, de entes subnacionais assumirem a cadeira do Estado-nação no interior do Conselho de Ministros - o que tem sido praticado por Länder alemães, austríacos e regiões belgas -, como também a possibilidade de participação freqüente de funcionários regionais no gerenciamento dos fundos estruturais e, ainda, a constante formação de redes setoriais entre os atores estatais subnacionais.

24 "Globalization and the rise of transnational regimes, especially regional trading areas, have eroded the distinction between domestic and foreign affairs and by the same token have transformed the division of responsibilities between state and subnational governments".

25 "Paradiplomacy is not the same as conventional state diplomacy, which is about pursuing a defined state interest in the international arena. It is more functionally specific and targeted, often opportunistic and experimental. [.. .] Paradiplomacy is also characterized by a high degree of involvement of civil society and the private sector".

26 "En la disputa de las papeleras la contienda se establece entre, por um lado, el Estado uruguayo, que concentra um mayor poder de decisión en el caso, y, por outro, uma elusiva amalgama formada por el gobierno nacio- 
nal argentino, el gobierno de Entre Rios y sectores de la sociedad civil. Considerando la paradiplomacia como un epifenómeno em el cuadro uruguayo y enfocando en la problemática de la cuestión subnacional en la Argentina, la rationale de esa amalgama parece repousar sobre tres factores basilares: 1. la utilización coherente del régimen internacional que rige lãs cuestiones ecológicas; 2. la capacidad de Entre Rios de mover uma acción colectiva parroquial conjugando intereses gubernamentales y no gubernamentales; 3 . la habilidad del gobierno federal de apropriarse de la bandera del movimiento infraestatal, subscribiéndolo internacionalmente".

27 "The term constituent diplomacy is intended to be a neutral descriptor, one that avoids the implication that the activities of constituent governments are necessarily inferior, ancillary, or supplemental to the high politics of nation-state diplomacy. What is high or low politics depends on one's perspective".

28 Apesar de não ser uma especificidade dos Estados-nação federais democráticos ou seus assemelhados, a constituent diplomacy tem sido mais praticada por eles.

29 " [. . . whatever competition may exist, and exist legitimately, within other policy fields, in foreign affairs the seemingly instinctual reaction of national élites is to try to suppress competition and shield foreign-policymaking behind a veil of state secrecy. The nation, it is said, must speak with a single voice".

30 Esta noção é explorada por Rawls: "De alguma maneira devemos anular os efeitos de contingências específicas que colocam os homens em desacordo, tentando-os a explorar circunstâncias naturais e sociais em benefício próprio. Agora, para fazer isso, assumo que as partes estão situadas atrás de um véu de ignorância. Elas não sabem como as várias alternativas afetarão seu caso particular e são obrigadas a avaliar os princípios somente com base em considerações gerais" (1999, p. 118). ["Somehow we must nullify the effects of specific contingencies which put men at odds and tempt them to exploit social and natural circumstances to their own advantage. Now in order to do this I assume that the parties are situated behind a veil of ignorance. They do not know how the various alternatives will affect their own particular case and they are obliged to evaluate principles solely on the basis of general considerations".]

31 "The politics of many international negotiations can usefully be conceived as a two-level game. At national level, domestic groups pursue their interests by pressuring the government to adopt favorable policies, and politicians seek power by constructing coalitions among those groups. At the international level, national governments seek to maximize their own ability to satisfy domestic pressures, while minimizing the adverse consequences of foreign developments. Neither of the two games can be ignored by central decision-makers, so long as their countries remain interdependent, yet sovereign",
32 Uma das possíveis fontes de inspiração para o princípio de subsidiaridade é a Encíclica Quadragésimo Anno, escrita por Pio XI em 1931. Nela diz o Sumo Pontífice: "Verdade é, e a história o demonstra abundantemente, que, devido à mudança de condições, só as grandes sociedades podem hoje levar a efeito, o que antes podiam até mesmo as pequenas; permanece, contudo, imutável aquele solene princípio da filosofia social: assim como é injusto subtrair aos indivíduos o que eles podem efetuar com a própria iniciativa e indústria, para o confiar à coletividade, do mesmo modo passar para uma sociedade maior e mais elevada o que sociedades menores e inferiores podiam conseguir, é uma injustiça, um grave dano e perturbação da boa ordem social. O fim natural da sociedade e da sua ação é coadjuvar os seus membros, não destruí-los nem absorvê-los" (Pio XI, 1969, p. 36).

33 Estamos considerando o Mercosul sem seus membros associados, ou seja, formado apenas por Argentina, Brasil, Paraguai e Uruguai. São apenas esses países que participam de forma plena da dinâmica institucional.

34 "More significant in the long run were the painfully slow negociation to include Argentina and the rest of Mercosur in the free trade area contemplated by the United States in its treaty with México and Canada".

35 " [...] no final de 1990, acadêmicos começaram a clamar por um segundo movimento na análise institucional, isto é, um diálogo mais construtivo que explorasse os caminhos nos quais estes paradigmas [escolha racional, histórico e organizacional] pudessem se complementar" (Campbell, 2004, p. 4). ["in the late 1990s scholars began calling for a second movement in institutional analysis, that is, a more constructive dialogue that explores the ways in which these paradigms [rational choice, historical and organizational] might complement and connect to each other favor.]

36 Vale lembrar a dita Guerra do Paraguai e suas conseqüências nefastas sobretudo para o povo guarani (Chiavenatto, 1979). Para uma reflexão literato-filosófica sobre o poder ditatorial na América Latina e sobre a figura polêmica de José Gaspar de Francia e sua importância para o desenvolvimento paraguaio, ver Roa Bastos (1974).

37 É verdade que as Províncias Unidas do Rio da Prata, hoje Argentina, tiveram uma experiência confederativa importante até 1860 . Mas desde então a hegemonia bonarense se faz sentir constitucionalmente de maneira sistemática. Isso mudará um pouco, como veremos a seguir, com a reforma constitucional de 1994.

38 Ver, por exemplo, a República da Venezuela que, após a chegada de Hugo Chavez ao poder, passou a chamarse República Bolivariana de Venezuela. Chavez solicitou ao Mercosul a adesão do seu país. A Decisão n. 29/05 do Mercosul estabelece que o Conselho Mercado Comum decide: "Acoger com satisfacción la solicitud de la República Bolivariana de Venezuela de incorporarse 
al Mercosur como Estado Parte" (Art. 1). O populismo clássico de Chavez ancora-se sobre a pré-disposição positiva que a percepção popular tem das idéias integracionistas e anti-imperialistas de Bolívar.

39 'La Constitution de 1988 étend jusqu'à un certain point la compétence législative des États. Elle fait également bénéficier les autorités municipales de cette extension".

40 Já em 1996 o então chanceler brasileiro, Luiz Felipe Lampreia, afirmava: "Novos temas, novas formas de interação entre as Chancelarias e entre essas e os demais órgãos governamentais e da sociedade civil, os imperativos da diplomacia pública e federativa, os imperativos da diplomacia de Chefes de Estado e Governo, marca exponencial do nosso tempo, a informatização, a busca de eficiência e de economicidade na gestão da máquina administrativa federal - essa é uma complexa realidade que aponta a necessidade da permanente atualização do Itamaraty, da carreira diplomática e dos nossos métodos de trabalho". Discurso proferido pelo Senhor Ministro das Relações Exteriores, Embaixador Luiz Felipe Lampreia por ocasião da cerimônia de formatura da turma "Florestan Fernandes" do Instituto Rio Branco em 30 de abril de 1996.

41 Fomos convidados pelo Sr. Vicente Trevas, titular da Subchefia de Assuntos federativos e Coordenador Nacional do Foro Consultivo de Municípios, Estados Federados, Províncias e Departamentos do Mercosul, para participar das discussões preliminares visando à realização do Seminário de Tucumán, na condição de experto universitário. O objetivo principal foi tentar organizar um seminário técnico antes do encontro dos governadores. Esse seminário técnico teve dois objetivos: dar visibilidade às duas regiões envolvidas; sugerir recomendações aos governadores. Por outro lado, teve três vertentes: Academia; Gestão Pública; e Empresas.

42 Contrariamente à Argentina ou aos Estados-Unidos, que resultam da união entre entes soberanos, o Brasil federaliza-se, em 1889, a partir de uma monarquia centralizada. Trata-se de um federalismo invertido, em que o poder central transfere competências às suas partes; e não de um federalismo tradicional, em que as partes renunciam competências em favor do centro (Abrucio, 1998).

43 “ $[. .$.$] que deleguen competencias y jurisdicción a orga-$ nizaciones supraestatales em condiciones de reciprocidad e igualdad, y que respeten el orden democrático y los derechos humanos. Las normas dictadas en su consecuencia tienen jerarquía superior a las leys".

44 "[...] celebrar convênios internacionales en tanto no sean incompatibles con la política exterior de la Nación y no afecten las facultades delegadas al Gobierno federal o el crédito público de la Nación; con conocimiento del Congreso Nacional".

45 "A Lei de Responsabilidade Fiscal — LRF (Lei Complementar n. 101, de 04 de maio de 2000) estabelece normas de finanças públicas voltadas para a responsa- bilidade na gestão fiscal, mediante ações em que se previnam riscos e corrijam os desvios capazes de afetar o equilíbrio das contas públicas, destacando-se o planejamento, o controle, a transparência e a responsabilização, como premissas básicas”. Definição capturada em 30/04/06 no site oficial do Ministério da Fazenda do governo brasileiro (http://www.tesouro.fazenda. gov.br/hp/lei_responsabilidade_fiscal.asp).

46 "Crear el Foro Consultivo de Municípios, Estados Federados, Provincias y Departamentos del Mercosur, con la finalidad de estimular el diálogo y la cooperación entre las autoridades de nível municipal, estadual, provincial y departamental dos Estados Partes del Mercosur". Mercosur/CMC/DEC. n. 41/04, art. 1 (site http:// www.mercosur.int/msweb/, acessado em 14/2/2005).

47 Devido à extensão da denominação do fórum, doravante, por uma questão de comodidade vocabular, o denominaremos Fórum das Unidades Estatais Subnacionais - FUES.

48 Mercosur /GMC/RES. N. 90/00 (site http://www. mercosur.int/msweb/, acessado em 01/5/2006).

49 "[...] opportunities for regions to act in Europe remain limited and states are still the dominant actors".

50 Protocolo relativo ao papel dos parlamentos nacionais na União Européia - Tratado de Lisboa.

51 Tratado de Lisboa (Art. 9A).

52 "[...] enhance democracy and increase legitimacy in the functioning of the Union". Informação disponível no site oficial da União Européia, http://europa.eu/ lisbon_treaty/glance/index_en.htm (acessado em 21/ 2/2008)

53 " [...] one of the most contentious questions of our era [is] whether globalization is draining away the political lifeblood of the nation-state, its sovereinty".

54 "The State is not disappearing; it is disaggregating into its component institutions".

55 "New demands are made for regional and local autonomy as groups find themselves buffeted by global forces and by inappropriate or ineffective political regimes. [...] They portend a political order of democratic associations, cities and nations as well as of regions and global networks. In such an order, the principle of autonomy would be entrenched in diverse sites of power and across diverse spatial domains".

56 "[...] se inició el camino de un necesario perfectionamiento institucional del proceso de integración".

\section{BIBLIOGRAFIA}

ABRUCIO, F. L. (1998), Os barões da Federação. São Paulo, USP/Hucitec. 
ALMEIDA, Paulo R. (1998), Mercosul: fundamentos e perspectivas. São Paulo, LTr.

ALMOND, G. \& VERBA, S. (1963), The civic culture. Boston, Little Brown.

BADIE, Bertrand. (1995), La fin des territories: essai sur le désordre international et sur l'utilité social du respect. Paris, Fayard.

BANCHOFF, Thomas \& SMITH, Mitchell P. (1999), Legitimacy and the European Union. Londres, Routledge.

BARBOSA, Rubens A. (1996), "O Brasil e a integração regional: a Alalc e a Aladi (1960-1990)", in José A. G. Albuquerque, Sessenta anos de política externa brasileira (1930-1990): diplomacia para o desenvolvimento. São Paulo, Cultura Editores Associados/Nupri-USP/Fapesp.

BATISTA JR., Paulo Nobueira. (2007), “A Argentina em apuros". Folha de São Paulo, site http:/ /www1.folha.uol.com.br/fsp/dinheiro/ fi2102200806.htm (acessado em 21/2/2008).

BRESSER PEREIRA, Luiz Carlos \& CUNILL GRAU, Nuria. (1999), O público não-estatal na reforma do Estado. Rio de Janeiro, Fundação Getúlio Vargas, Rio de Janeiro.

BROWN, Chris; NARDIN, Terry \& RENGGER, Nicholas. (2002), International relations in political thought. Cambridge, Cambridge University Press.

CAMARGO, Sônia. (2006), "Mercosul: crise de crescimento ou crise de terminal". Lua Nova, 68: 57-90.

CAMPBELL, John L. (2004), Institutional change and globalization. Princeton, Princeton University Press.

CARVALHO, Ernani Rodrigues de. (2004), “Em busca da judicialização da polítcia no Brasil: apontamentos para uma nova abordagem”. Revista de Sociologia e Politica, 23: 115-126.

CERVO, Amado Luiz \& BUENO, Clodoaldo. (2002), História da política exterior do Brasil. Brasília, Editora da UnB.

CHIAVENTATO, Julio José. (1979), Genocídio americano: a Guerra do Paraguai. São Paulo, Brasiliense.
DAHL, Robert. (1989), Democracy and its critics. New Haven, Yale University Press.

DE LA SERE, Françoise. (1992), "Le Traité de l'Union Européenne”. Regards sur l'Actualité, 180: 3-22.

DEUTSCH, Karl W. (1981), "The crisis of the State". Government and Opposition, 16 (3): 331-343.

ELIAS, Norbert. (1987), La société des individus. Paris, Fayard.

FOLHA DE SÃO PAULO. (2008), "Manifesto dá a Sarkozy estilo monárquico", site http:// www1.folha.uol.com.br/fsp/mundo/ ft1802200820.htm (acessado em 18/2/2008).

FRAZÃO, Armando S. (1994), "Brésil", in Denis Rougemont, Dictionnaire international du fédéralisme. Bruxelles, Bruylant.

GRANT, Ruth W. \& KEOHANE, Robert O. (2005), "Accountability and abuses of power in world politics". American Political Science Review, 99 (1): 29-43, fev.

HABERMAS, Jürgen. (1991), The structural transformation of the public sphere. Cambridge, MIT Press.

HELD, David. (1996), Models of democracy. Stanford, Stanford University Press.

HOCKING, Brian. (2004), "Regionalismo: uma perspectiva das relações internacionais", in Tullo Vigevani et al. (orgs.). A dimensão subnacional e as relaçoes internacionais, São Paulo, Educ/ Unesp/Edusc, pp. 77-107.

HOFFMANN, Andrea Ribeiro \& VAN DER VLEUTEN, Anna. (2007), Closing or widening the gap? England, Ashgate.

JENKINS, Rob. (2003), “India's States and the makilg of foreign economic policy: the limit of the constituent diplomacy paradigm". Publius: The Journal of Federalism, 33 (4): 63-82, Fall.

KEATING, Michael. (1999), "Regions and international affairs: motives, opportunities and strategies", in Francisco Aldecoa e Michael Keating, Paradiplomacy in action: the foreign relations of subnational governments. Londres, Frank Cass.

KELSEN, Hans. (1992), Teoria geral do direito e do Estado. São Paulo, Martins Fontes. 
KEOHANE, Robert \& NYE, Joseph. (1987), "Power and interdependence reviseted". International Organization, 41: 725-753.

KINCAID, John. (2001), “Constituent diplomacy in federal polities and the Nation-state: conflict and co-operation", in Hans J. Michelmann e Panayotis Soldatos, Federalism and international relations: the role of subnational units. Oxford, OUP.

KRASNER, Stephen. (1988), "Sovereignity: an institutional perspective", Comparative Political Studies, 21: 66-94.

KULGEMAS, Eduardo \& BRANCO, Marcello S. (2005), "Os governos subnacionais e a nova realidade do federalismo", in Tullo Vigevani et al., Governos subnacionais e sociedade civil: integração regional e Mercosul. São Paulo, PUC-SP/ Unesp/Fapesp.

LAÏDI, Zaki. (1993), "Sens et puissance dans le sistème international”, in Zaki Laïdi, L'ordre mondial relâché: sens et puissance après la Guerre Froide. Paris, Presses de la Fondation Nationale de Sciences Politiques.

LEGAL, Hubert. (2001), "Composition et fonctionnement des Cours Européennes". Pouvoirs, 96: 65-84.

LIMONGI, Fernando. (2006), "Presidencialismo, coalizão partidária e processo decisório". Novos Estudos do Cebrap, 76: 17-41, nov.

MAJONE, Giandomenico. (1996), Regulating Europe. Londres, Routledge.

MEDEIROS, Marcelo A. (2000), La genèse du Mercosud. Paris, L'Harmattan.

(2003), "Prerrogativas estatais, integração regional e lógica distributiva”. Lua Nova, 58: 141-168.

(2004), "Unidades subnacionais e integração européia: o caso do comitê das regiões", in Tullo Vigevani et al., A dimensão subnacional e as relações internacionais. São Paulo, Educ/Unesp/Edusc.

MENY, Yves. (1993), Les politiques du mimétisme institutionnel: la greffe et le rejet. Paris, L'Harmattan.

MOE, T. (1984), "The new economics of organization". American Journal of Political Science, 28: 739-777.
MORAVCSIK, Andrew. (2002), "In defense of the democratic deficit: reassessing legitimacy in the European Union". Journal of Common Market Studies, 40 (44): 603-624.

NICOLAIDIS, Kalypso \& HOWSE, Robert. (2001), "The federal vision, levels of governance and legitimacy", in Kalypso Nicoladis e Robert Howse, The federal vision. Oxford, OUP.

O’DONNELL, Guillermo. (1999), "Teoria democrática e política comparada". Dados, 42 (4): 655-690, Rio de Janeiro.

OHMAE, Kenichi. (1995), The end of the Nation State: the rise of regional economies. Nova York, Haper Collins.

PAQUIN, Stéphane. (2004), Paradiplomatie et relations internationales. Bruxelles, Peter Lang.

PENA, Félix. (2005), “Assimetrias e medidas de convergência estructural: enfoques y propuestas para un Mercosur solidario". Site http:/ / www. sice.oas.org/agreements/Mercin_s. asp\# MERCOSUR (acessado em 23/1/2006).

PIO XI. (1969), Carta Encíclica de Sua Santidade Pio XI: sobre a restauração e aperfeiçoamento da ordem social em conformidade com a lei evangélica. São Paulo, Edições Paulinas.

PRZERWOSKI, Adam. (1985), Capitalism and social democracy. Cambridge, Cambridge University Press.

PUTNAM, Robert. (1988), "Diplomacy and domestic politics: the logic of two-level games". International Organization, 42: 427-560.

RAWLS, John. (1999), A theory of justice. Massachusetts, Belknap.

ROA BASTOS, Augusto. (1974), Yo el supremo. Buenos Aires, Siglo XXI.

ROSENAU, James. (1990), Turbulence in world politics. Princeton, Princeton University Press.

SALOMÓN, Mônica \& NUNES, Carmen. (2007), "A ação externa dos governos subnacionais no Brasil - os casos do Rio Grande do Sul e de Porto Alegre: um estudo comparativo de dois tipos de atores mistos". Contexto Internacional, 29 (1): 99-146. 
SARAIVA, Miriam Gomes \& MEDEIROS, Marcelo de Almeida. (2007), "La crisis de las papeleras y los actores subnacionales en el Mercosur", in Vicente Palermo e Carlos Reboratti, Del otro lado del río. Buenos Aires, Edhasa.

SARTORI, Giovanni. (1965), Teoria democrática. Lisboa, Editora Fundo de Cultura.

(1987), The theory of democracy revisited. Chatham, Chatham House Publishers.

SCHARPF, Fritz. (1996), "Negative and positive integration in the political economy of European Welfare States", in Gary Marks et al., Governance in the European Union. Londres, Sage.

(2000), Gouverner l'Europe. Paris, Presses de Sciences Po.

SCHUMPETER, Joseph A. (1975), Capitalism, socialism and democracy. Nova York, HarperPerennial.

SCHMITTER, Philippe. (2000), How to democratize the European Union. . . And why bother? Boulder, Rowman \& Littlefield.

SCHMITTER, Philippe \& KARL, Terry Lynn. (1993), "What democracy is. . . and is not", in L. Diamond e M. F. Plattner (eds.), The global resurgence of democracy. Londres, The Johns Hopkins University Press, pp. 39-52.

SHIPMAN, Alan. (2002), The globalization myth. Cambridge, Icon Books.

SLAUGHTER, Anne-Marie. (1999), The role of law in international politics. Oxford, OUP.

TRAITÉS DE ROME, MAASTRICHT ET AMSTERDAM. (1999), Textes compares. Paris, La Documentation Française.

TRATADO DE LISBOA. (2007), Jornal oficial da União Européia, C 306/148 PT, 17/12/2007.

TULCHIN, Joseph S. (1998), "Continuity and change in Argentine foreign policy", in Joseph S. Tulchin e Allison M. Garland, Argentina: the challenges of modernization. Washington, SR Books.

VAZ, Alcides C. (1999), "Parcerias estratégicas no contexto da política externa brasileira: implicações para o Mercosul". Revista Brasileira de Politica Internacional, 42 (2): 52-80, Brasília.
VIGEVANI, Tullo et al. (2004), A dimensão subnacional e as relações internacionais. São Paulo, Educ/ Unesp/Edusc. 


\section{LEGITIMIDADE, DEMOCRACIA E ACCOUNTABILITY NO MERCOSUL}

\section{Marcelo de Almeida Medeiros}

Palavras-chave: Legitimidade; Democracia; Responsabilidade; Governança; Mercosul.

O Mercosul reflete, ao lado de inúmeros outros processos de organização regional internacional, as conseqüências de um processo de mutação do Estado-nação, que parece não mais conseguir atuar como primo regulador da vida social. A percepção dessa mudança, no entanto, persiste ancorada em padrões interpretativos ainda por demais tributários da lógica estato-cêntrica. A cartografia institucional que daí deriva encerra incoerências e incompatibilidades entre de um lado, a demanda real dos atores sociais e agentes econômicos e, de outro, as instituições políticas de fato concebidas e implementadas. Este artigo propõe-se a investigar como o fenômeno da governança tem se transformado no seio do Mercosul. O autor detém-se nas complexas e imbricadas relações entre os níveis regional, nacional e, sobretudo, subnacional, privilegiando os nexos institucionais que dai derivam.

\section{LEGITIMACY, DEMOCRACY, AND ACCOUNTABILITY WITHIN MERCOSUR}

\section{Marcelo de Almeida Medeiros}

Keywords: Legitimacy; Democracy; Accountability; Governance; Mercosur.

Mercosur reflects, as many other Regional Integration Processes do, the consequences of a process of Nation-State mutation, as this Nation-State seems incapable of keeping acting as the vital regulator of social life. Nevertheless, the perception of this mutation persists anchored on Nation-State interpretations' patterns. The institutional cartography that emerges from this situation encloses some inconsistencies and incompatibilities between: on the one hand, the real demands of social actors and economic agents; and, on the other hand, the de facto political institutions shaped. This article proposes to investigate how governance has been transformed within Mercosur. It focus on the intricate and complex relations between regional, national and, particularly, sub-national levels. It is composed by two parts: the first seeks to situate the problem of the relationship between legitimacy, democracy, and accountability in the sphere of regional governance and the action of sub-national actors; the second, under this prism, inquires, empirically, about the Brazilian-Argentinean connections and about the institutional design and relationship networks in Mercosur.

\section{LÉGITIMITÉ, DÉMOCRATIE ET ACCOUNTABILITY} DANS LE MERCOSUR

\section{Marcelo de Almeida Medeiros}

Mots-clés: Légitimité; Démocratie; Responsabilité; Gouvernance; Mercosur.

Le Mercosur reflète, aux côtés d'autres processus d'organisation régionale internationale (ORI), les conséquences d'un processus de mutation de l'État-nation, qui semble ne plus être capable de jouer le rôle de principal régulateur de la vie sociale. La perception de cette mutation demeure, néanmoins, ancrée à des paramètres d'interprétation tributaires d'une logique régalienne. La cartographie institutionnelle qui en découle abrite, de ce fait, des incohérences et des incompatibilités entre, d'une part, la demande réelle des acteurs sociaux et des agents économiques et, d'autre part, les institutions politiques concrètement conçues et mises en place. Cet article propose une analyse sur le développement du phénomène de la gouvernance au sein du Mercosur. L'auteur concentre son attention dans les rapports entre les niveaux régional, national et, surtout, sous-national, en privilégiant les liens institutionnels qui en découlent. 